\title{
Fomento às inovações nas micro e pequenas empresas - avaliação das empresas baianas sobre editais de subvenção econômica
}

\begin{abstract}
RESUMO
O objetivo deste artigo foi identificar as principais dificuldades e oportunidades vivenciadas pelas empresas baianas contempladas nos editais de Subvenção Econômica da Fundação de Amparo à Pesquisa do Estado da Bahia (FAPESB) no período de 2008 a 2010. Para o alcance dos objetivos, foram entrevistados os responsáveis pelas empresas contempladas nos editais 001/2008, 017/2008, 008/2010 e 023/2010, além de ter sido feita a análise dos referidos editais. As principais dificuldades relatadas pelas empresas entrevistadas foram o excesso de burocracia, a exigência de contrapartida e os atrasos no cumprimento dos prazos da FAPESB, sobretudo do repasse dos recursos. As oportunidades apontadas foram o desenvolvimento de novos projetos de pesquisa, o aumento do potencial competitivo, a abrangência de novos mercados e o fortalecimento das suas marcas. A principal ameaça identificada foi a possibilidade de inadequação dos editais à realidade particular apresentada pelas Micro e Pequenas Empresas (MPEs) baianas. Espera-se que o presente artigo possa fornecer subsídios e contribuir para elaboração e fortalecimento de políticas públicas que visem ao desenvolvimento das MPEs, principalmente no alcance de fomento público à inovação.
\end{abstract}

Palavras-chave: Gestão da Inovação. Subvenção econômica. Micro e Pequena Empresa.

Fabiana Carneiro Silva de Holanda fabianaholanda2010@hotmail.com Graduanda em Línguas Estrangeiras Aplicadas às Negociações Internacionais Agente de Inovação da Agroindústria na Universidade Estadual de Santa Cruz

Ticiana Grecco Zanon Moura ticianaz@hotmail.com

Mestre em Economia aplicada pela Universidade Federal de Pernambuco Professora do Departamento de Letras e Artes/ UESC, Ilhéus/BA, Brasil Alzir Antonio Mahl alzir_mahl@hotmail.com 


\section{DELIMITAÇÃO DO TEMA E DO PROBLEMA DA PESQUISA}

O tema inovação tecnológica vem ocupando lugar de destaque na agenda econômica de diversos países. Considerada como chave propulsora para o crescimento econômico, a inovação tem se tornado o fator diferencial para a obtenção de vantagem competitiva num mercado cada vez mais global e dinâmico (HOLANDA et al., 2013).

Ao mesmo tempo, a preocupação com o potencial inovador nas Micro e Pequenas Empresas (MPEs) tem se mostrado latente, sobretudo porque, de acordo com Fonseca e Kruglianskas (2002), esse segmento empresarial é o maior ofertante de postos de trabalho em economias como a brasileira, além de ser responsável pela movimentação da economia em atividades essenciais à sobrevivência de diversos países (MAÇANEIRO, 2008).

Atento a essa realidade, o governo brasileiro vem investindo e lançando programas de fomento às inovações nas MPEs. Um exemplo são os editais de subvenção econômica que, no estado da Bahia, foram iniciados em 2008 pela Fundação de Amparo à Pesquisa do Estado da Bahia (FAPESB).

Os programas de fomento à inovação, especialmente os editais de subvenção econômica, são uma realidade recente dentro do cenário nacional, e eles possuem uma elevada importância para as MPEs no que diz respeito ao desenvolvimento de projetos de pesquisa e desenvolvimento (P\&D).

Portanto, conhecer alguns aspectos e detalhes ocorridos na relação entre as MPEs e as agências de fomento no momento da participação dessas empresas no processo de seleção dos editais de subvenção e desenvolvimento das propostas é um aspecto de suma importância para orientar as políticas públicas e nortear as ações dos editais que venham a surgir.

Os editais de subvenção da FAPESB possuem a prerrogativa de que exclusivamente as empresas com registro na Junta Comercial do estado da Bahia estão aptas a participarem do processo de seleção do referido tipo de edital. Nesse contexto, o objetivo desta pesquisa foi identificar as principais dificuldades e oportunidades pelas quais passaram as empresas baianas contempladas nos editais de subvenção econômica 001/2008, 017/2008, 008/2010 e 023/2010 da FAPESB com a expectativa de fornecer subsídios e contribuir para a elaboração e fortalecimento de políticas públicas que visem ao desenvolvimento das MPEs baianas, sobretudo no alcance de fomento público à inovação.

Ressalta-se que, para fins de análise de dados e discussões do presente trabalho, foi considerado o conceito de Micro e Pequena Empresa estabelecido pelo Serviço de Apoio à Micro e Pequena Empresa (SEBRAE), no Anuário de Trabalho publicado em 2012.

De acordo com o Anuário de Trabalho publicado pelo SEBRAE (2012), são consideradas Micro Empresas aquelas com 0 a 19 pessoas ocupadas, e Pequena Empresa, de 20 a 99.

Ainda para fins de análise, foi utilizada a classificação descrita pela FAPESB em seus editais nos quais Micro Empresa é aquela que possui receita anual até 360 mil reais, e Pequena Empresa a que possui receita anual entre 361 mil a 3,6 milhões de reais.

O presente artigo divide-se em sete seções, das quais a primeira é esta introdução, seguida da apresentação da realidade das MPEs no que se refere aos seus principais pontos fortes e pontos fracos para promover a inovação; a terceira seção traz informações sobre a política recente de CT\&l do Brasil e os programas de subvenção econômica. Já a quarta discorre acerca do programa de Subvenção Econômica PAPPE e das Fundações de Amparo à Pesquisa (FAP), como também apresenta o referido programa no estado da Bahia; a quinta expõe a metodologia utilizada para alcance dos objetivos da pesquisa.

Os dois tópicos seguintes apresentam os resultados e as discussões do artigo e, finalmente, o último refere-se às conclusões dos autores.

\section{INOVAÇÃO NAS MPES}

De uma forma geral, bem como no contexto da Gestão da Inovação, as MPEs, quando comparadas às grandes empresas, possuem vantagens inerentes à sua própria condição estrutural. A vantagem comparativa delas é atribuída à flexibilidade associada a uma organização mais enxuta. Elas conseguem prover um rápido e eficiente serviço, além de estarem mais próximas dos seus clientes, o que possibilita uma melhor adaptação de produtos a demandas de clientes variados (BALDWIN; GELLATLY, 2003 apud MAÇANEIRO, 2008).

Segundo Coral e Geisler (2011), nas pequenas empresas, há uma ligação eficiente entre marketing/produção e uma rápida tomada de decisão para o $\mathrm{P} \& D$. Nesse processo, além de envolver poucas pessoas, os custos iniciais para o desenvolvimento geralmente é baixo, não há tantas 
amarras burocráticas como nas grandes empresas, e as intenções de $\mathrm{P} \& \mathrm{D}$ rapidamente chegam aos tomadores de decisão, agilizando o processo de inovação.

Porém, em contrapartida, as autoras identificaram como barreiras à própria natureza de incerteza e de alto investimento de todo o processo de P\&D (muitas vezes as pequenas empresas colocam-se em situação de vulnerabilidade perante o mercado quando investem uma grande parte dos seus recursos em poucos ou em um único projeto de inovação) a falta de continuidade de investimentos, na fase final do projeto, e a dificuldade de fomentar a compra das matérias-primas para produção da inovação.

Coral et al. (2011) salientam que o Brasil possui um grande número de MPEs com grande potencial inovador, mas com dificuldades de concretizar suas ideias em virtude das restrições de recursos financeiros e humanos. O gargalo principal para que tais empresas desenvolvam inovações é, além da ausência de capital humano capacitado, o fator financeiro.

As MPEs apresentam dificuldades diversas para conseguir financiamentos, sobretudo fomento público. Segundo Morais (2008a), as dificuldades vão desde a oferta de garantias para os financiamentos, o excesso de burocracia evidenciado nos processos de pedido de crédito até falhas estruturais da empresa, como informalidade nos negócios, baixa transparência nos registros contábeis e documentações legais, e, por fim, a inadequada administração financeira do negócio.

No que se refere ao financiamento, esse pode ser um fator determinante para inovação em MPE, que não carece de fundos próprios para conduzir projetos de inovação e enfrenta muito mais dificuldades para obter financiamento externo do que as grandes empresas (OCDE, 2005 apud MAÇANEIRO, 2008). Além disso, de acordo com Maçaneiro (2008), o custo elevado do projeto de inovação, os riscos excessivos e a falta de recursos próprios são razões para que as MPEs busquem fontes de financiamento para seus projetos de P\&D.

No universo das MPEs, o acesso ao crédito e as iniciativas inovadoras estão intimamente ligados. Aquelas MPEs que conseguem investir em inovação e, portanto, possuem fomento externo para tal, tornam-se mais competitivas, e a consequência disso é percebida na própria taxa de sobrevivência das empresas.

O financiamento externo possui um grande impacto e importância nas estratégias das inovações das MPEs. Nesse contexto, as políticas públicas de Ciência, Tecnologia e Inovação (CT\&l), voltadas para o fomento e apoio de projetos de pesquisa e desenvolvimento nas MPEs, são iniciativas positivas para alavancar o crescimento e desenvolvimento dessas modalidades de empresas dentro do cenário nacional, ou mesmo no internacional.

\section{POLÍTICA DE CT\&I DO BRASIL E OS PROGRAMAS DE SUBVENÇÃO ECONÔMICA}

O Brasil, nas últimas três décadas, tem sedimentado bases para promover a inovação e fortalecer o potencial competitivo da indústria nacional.

No fim da década de 1990, foram estabelecidos, pelo governo brasileiro, novos instrumentos de financiamento e de estímulo à inovação, baseados em incentivos fiscais, em fundos setoriais para o desenvolvimento de projetos e na diversificação de distribuição dos recursos financeiros para P\&D, que antes eram destinados apenas às universidades, e que passaram também a ser direcionados às empresas nacionais.

Segundo Corder (2006), essas mudanças representaram uma nova postura da Política de Ciência e Tecnologia no tocante às necessidades do Sistema Nacional de Inovação.

O intuito do Estado brasileiro na elaboração das novas políticas públicas era dividir os custos e os riscos da atividade de P\&D com o setor produtivo (LIMA; TEIXEIRA, 2001) e possibilitar, assim, maior incentivo à inovação e, consequentemente, ganho de competitividade do produto nacional.

Nesse contexto, a criação dos fundos setoriais, instituídos por meio de leis federais de iniciativa do Ministério de Ciência, Tecnologia e Inovação (MCTI), buscou ampliar as fontes de financiamento não reembolsáveis, por intermédio dos recursos arrecadados ao Orçamento da União, direcionados especificamente à CT\&I (MORAIS, 2008b).

De acordo com Pereira e Figueiredo (2006), esses fundos possuem receitas vinculadas a um fim específico, oriundas de contribuições incidentes sobre o faturamento de empresas e/ou sobre o resultado da exploração de recursos naturais pertencentes à União, e são alocados no Fundo Nacional de Desenvolvimento Científico e Tecnológico (FNDCT), cuja secretaria executiva está a cargo da Financiadora de Estudos e Projetos (FINEP), ligada ao MCTI.

Além das medidas estabelecidas nos anos de 1990, a década seguinte também representou 
importantes mudanças no cenário de inovação do Brasil. A partir de 2004, foram promulgadas diversas leis de incentivo à inovação. A primeira, a Lei de Inovação (n॰ 10.973/04), regulamentava a parceria entre universidade-empresa para desenvolvimento de projetos de pesquisa e versava sobre medidas de incentivo à inovação e à pesquisa científica e tecnológica no ambiente produtivo, com vistas à capacitação e ao alcance da autonomia tecnológica e ao desenvolvimento industrial do país (BRASIL, 2004b).

Posteriormente, foram promulgadas a Lei de Informática - Lei no 11.077/04 (BRASIL, 2004a), a Lei do Bem - Lei no 11.196/05 (BRASIL, 2005) - e Lei Rouanet de pesquisa - Lei no 11487/07 (BRASIL, 2007), que procuravam estimular parcerias tecnológicas por meio de benefícios fiscais aos empresários.

A Lei de Inovação foi o regimento legal que previu o apoio à inovação nas empresas pela concessão de recurso financeiro em três modalidades distintas: subvenção econômica, financiamento e participação societária (BRASIL, 2004b).

Essa modalidade busca diversificar a distribuição de incentivos à inovação nas empresas de diferentes portes (micro, pequena, média e grande). Assim, esse sistema possui um percentual do recurso orçamentário destinado apenas às MPEs (MORAIS, 2008b). Por exemplo, a primeira chamada pública da FINEP (01/2006) para essa modalidade destinava, dos trezentos milhões do edital, sessenta milhões exclusivamente para MPEs.

Como a modalidade de subvenção econômica à inovação na empresa ainda é recente no Brasil, o número de projetos submetidos aos editais vem crescendo paulatinamente. De acordo com Maçaneiro (2008), o edital de subvenção econômica de 2006 da FINEP recebeu 1.100 propostas, das quais 145 foram aprovadas. Já em 2007, foram 2.567 propostas, com 174 empresas selecionadas para a fase final, e, em 2008, o número de projetos submetidos foi de 2.664, tendo 206 obtido êxito.

No que se refere à distribuição geográfica desses recursos, Andrade (2009) apresenta os dados dos anos de 2006 a 2009. Em seu estudo, o autor explica que $67 \%$ dos valores contratados nos editais de subvenção econômica foram direcionados a empresas da região sudeste, $19 \%$ para região sul, $8 \%$ para região nordeste e $3 \%$ para as regiões centro-oeste e norte.

O levantamento e acompanhamento dos dados a respeito da evolução dos editais de subvenção, e a distribuição dos recursos públicos por região são de grande importância para formulação de políticas públicas e elaboração de estratégias do MCTI que possibilitem a inserção de regiões menos favorecidas dentro do cenário de inovação nacional.

$\mathrm{Na}$ tentativa de diminuir a desproporção da distribuição de recurso e direcionar o fomento das chamadas públicas de subvenção para temas estratégicos de interesse do arranjo produtivo local, a FINEP lançou a modalidade PAPPE Subvenção em parceria com as Fundações de Amparo à Pesquisa (FAP) estaduais que possuem como tarefa, segundo a FINEP (2013), a divulgação do programa às MPEs das suas respectivas regiões; a organização de todo o processo de candidatura de MPEs locais, estaduais ou regionais; a análise e seleção dos projetos contemplados; o gerenciamento e a operação da parte técnica e financeira do programa; o acompanhamento e a avaliação dos projetos selecionados para apoio, bem como a prestação de contas dos recursos gerenciados.

O Programa de apoio à pesquisa em empresas, na modalidade subvenção à micro e pequenas empresas - PAPPE Subvenção -, é coordenado pela FINEP em parceria com as Fundações de Amparo à Pesquisa regionais, estaduais ou locais, que são as executoras do programa em suas regiões de abrangência (MAÇANEIRO, 2008).

As FAPs operam como parceiras estratégicas da FINEP e agilizam o processo de contratação, pré-qualificando as propostas e elaborando pareceres técnicos dos projetos encaminhados pelas empresas (ANPEl, 2009).

\section{PROGRAMA PAPPE SUBVENÇÃO NO ESTADO DA BAHIA}

Em 2006, a FINEP lançou o edital 02/2006 cujos objetivos eram selecionar e repassar verba de subvenção econômica para organismos dos estados federativos interessados em fazer parte do mencionado programa. De acordo com Morais (2008b), a chamada recebeu 85 propostas, das quais dezessete foram selecionadas com um montante de contrapartida no valor de $\mathrm{R} \$ 95$ milhões, que, somados aos 150 milhões da chamada, totalizavam R\$245 milhões a serem aplicados em três anos.

Dos estados do nordeste, a Bahia foi quem recebeu maior volume de recurso, R\$ 11 milhões, ocupando o primeiro lugar da lista dos estados contemplados. Em seguida, Pernambuco com R\$ 10 milhões, Ceará com R\$ 6 milhões, Rio Grande do Norte com R\$ 3 milhões e Maranhão e Piauí, com R\$ 1 milhão cada um (MORAIS, 2008b). 
Vale ressaltar que, de acordo com Ferreira (2012), a subvenção econômica no estado da Bahia passou por dois momentos distintos. Até 2008, o apoio ocorria de forma indireta, em que os pesquisadores apresentavam propostas de inovação em parceria com empresas, que eram beneficiadas indiretamente, uma vez que os recursos eram destinados diretamente ao pesquisador, e a pesquisa acontecia dentro da universidade. Após 2008, as empresas já tinham a possibilidade de concorrer diretamente aos editais de subvenção econômica, com suas propostas de P\&D.

A mudança ocorreu em virtude da promulgação da Lei de Inovação Tecnológica da Bahia, Lei nº $11.174 / 2008$, que dispõe sobre incentivos à inovação e à pesquisa científica no Estado (SECTI, 2008).

$\mathrm{O}$ artigo 25 da lei em questão regula a participação do Estado no papel de fomentador e incentivador da inovação.

O Estado, por meio de seus órgãos da administração pública direta ou indireta, incentivará a participação de empresas nacionais no processo de inovação tecnológica, mediante o compartilhamento de recursos humanos, materiais e de infra-estrutura ou a concessão de apoio financeiro ou de incentivo fiscal a serem ajustados em acordos específicos (BRASIL, 2008).

O primeiro edital lançado pela Fundação de Amparo à Pesquisa do Estado da Bahia (FAPESB) foi o $001 / 2008$, com um montante total de recurso de R\$ 16,5 milhões (FAPESB, 2013). Esse edital recebeu 67 propostas, das quais dezoito foram aprovadas com um valor total de $R \$ 6,7$ milhões, restando o saldo de $\mathrm{R} \$ 9,8$ milhões (FERREIRA, 2012).

No segundo edital (017/208), das 83 propostas apresentadas, dezoito foram contempladas, e estas captaram juntas $\mathrm{R} \$ 7,7$ milhões. Já no terceiro, $008 / 2010$, quatorze projetos foram aprovados dos 48 submetidos, com o valor total de $\mathrm{R} \$ 3,9$ milhões, e o quarto teve dezesseis projetos aprovados, de 59 apresentados, que somaram R\$ 6,5 milhões em recursos não reembolsáveis (FAPESB, 2008b; 2008c; 2010a).

Dos editais analisados nesta pesquisa - 001/2008, 017/2008, 008/2010 e 023/2010 -, o valor total de recurso disponibilizado foi de R\$ 42,5 milhões, destes, R\$ 27,9 milhões foram aprovados e repassados às empresas (FAPESB, 2008a; 2008b; 2008c; 2010a; 2010b). A quantidade total de propostas submetidas nos editais estudados foi de 257 , das quais 66 foram aprovadas.

O Quadro 1 detalha as especificidades dos editais aqui examinados quanto aos recursos disponibilizados, à distribuição dos recursos, à exigência de contrapartida, ao valor das propostas submetidas e aprovadas e, finalmente, aos valores aprovados e ao saldo final.

A distribuição geográfica das empresas que participaram do processo seletivo é apresentada na Figura 1. Nota-se que a grande maioria das empresas é proveniente de Salvador ou da região metropolitana.

Figura 1 - Disposição geográfica das MPEs baianas que concorreram aos editais FAPESB

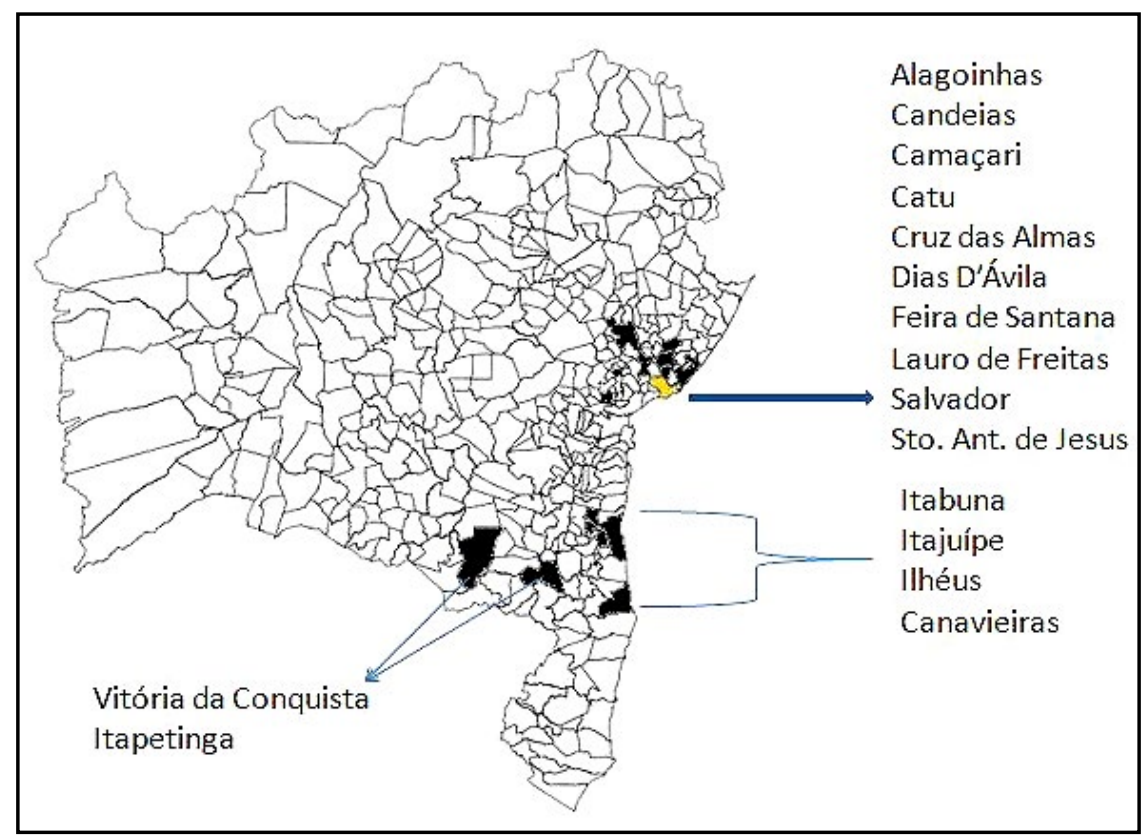

Fonte: Dados da pesquisa (2014) 
Quadro 1 - Detalhamento dos editais PAPPE Subvenção 001/2008, 017/2008, 008/2010 e 023/2010 da FAPESSB

\begin{tabular}{|c|c|c|c|c|c|c|c|}
\hline & $\begin{array}{c}\text { Recurso } \\
\text { disponibilizado }\end{array}$ & $\begin{array}{l}\text { Distribuição do } \\
\text { recurso }\end{array}$ & $\begin{array}{l}\text { Contrapartida } \\
\text { da empresa }\end{array}$ & $\begin{array}{l}\text { Projetos } \\
\text { submetidos }\end{array}$ & $\begin{array}{l}\text { Projetos } \\
\text { aprovados }\end{array}$ & $\begin{array}{l}\text { Recurso } \\
\text { aprovado }\end{array}$ & Saldo \\
\hline $001 / 2008$ & $\begin{array}{c}\text { R\$ } 16,5 \text { milhões } \\
\text { (R\$ } 5,5 \text { milhões } \\
\text { da FAPESB e R\$ } \\
11 \text { milhões da } \\
\text { FINEP). }\end{array}$ & $\begin{array}{c}\text { Máximo de } \mathrm{R} \$ \\
500 \text { mil por } \\
\text { projeto. No } \\
\text { mínimo } 30 \% \\
\text { do valor do } \\
\text { edital deveriam } \\
\text { ser destinados } \\
\text { às empresas } \\
\text { sediadas fora } \\
\text { da região } \\
\text { metropolitana } \\
\text { de Salvador. }\end{array}$ & & 67 & 18 & $\begin{array}{l}\mathrm{R} \$ 6,7 \\
\text { milhões }\end{array}$ & $\begin{array}{l}\mathrm{R} \$ 9,8 \\
\text { milhões }\end{array}$ \\
\hline $017 / 2008$ & $\begin{array}{c}\text { R\$ 9,8 milhões } \\
\text { (R\$ } 500 \text { mil da } \\
\text { FAPESB e R\$ } \\
\text { 9,3 milhões da } \\
\text { FINEP). }\end{array}$ & $\begin{array}{l}\text { Máximo de R\$ } \\
500 \text { mil por } \\
\text { projeto. No } \\
\text { mínimo } 30 \% \\
\text { do valor do } \\
\text { edital deveriam } \\
\text { ser destinados } \\
\text { às empresas } \\
\text { sediadas fora } \\
\text { da região } \\
\text { metropolitana } \\
\text { de Salvador. }\end{array}$ & $\begin{array}{c}\text { Mínimo } 30 \% \\
\text { do valor } \\
\text { solicitado } \\
\text { (financeira e/ou } \\
\text { não financeira) } \\
\text { para micro } \\
\text { e pequena } \\
\text { empresa. } \\
\text { Empresas } \\
\text { incubadas: } \\
\text { mínimo de } \\
\text { 10\% do valor } \\
\text { da proposta. }\end{array}$ & 83 & 18 & $\begin{array}{l}\mathrm{R} \$ 7,7 \\
\text { milhões }\end{array}$ & $\begin{array}{l}\mathrm{R} \$ 2,1 \\
\text { milhões }\end{array}$ \\
\hline $008 / 2010$ & $\begin{array}{l}\text { R\$ } 4 \text { milhões } \\
\text { (recursos } \\
\text { oriundos da } \\
\text { FINEP). }\end{array}$ & $\begin{array}{l}\text { Máximo de R\$ } \\
400 \text { mil por } \\
\text { proposta. }\end{array}$ & $\begin{array}{l}\text { Mínimo de } 30 \% \\
\text { do valor para } \\
\text { empresas de } \\
\text { pequeno porte } \\
\text { e mínimo de } \\
20 \% \text { para micro } \\
\text { empresas. }\end{array}$ & 48 & 14 & $\begin{array}{l}\mathrm{R} \$ 3,9 \\
\text { milhões }\end{array}$ & $\begin{array}{c}\mathrm{R} \$ 100 \\
\mathrm{mil}\end{array}$ \\
\hline $023 / 2010$ & $\begin{array}{l}\text { Modalidade } 1: \\
\text { R\$ } 14 \text { milhões. } \\
\text { Modalidade } 2: \\
\text { R\$ } 10 \text { milhões. } \\
\text { Valor total: } \mathrm{R} \$ 24 \\
\text { milhões (R\$ } 16 \\
\text { milhões da FINEP } \\
\text { e R\$ } 8 \text { milhões } \\
\text { da FAPESB). }\end{array}$ & $\begin{array}{l}\text { Modalidade 1: } \\
\text { R\$ } 400 \text { mil por } \\
\text { proposta. } \\
\text { Modalidade 2: } \\
\text { R\$ } 800 \text { mil por } \\
\text { proposta. }\end{array}$ & $\begin{array}{l}\text { Mínimo de } 10 \% \\
\text { da empresa } \\
\text { proponente } \\
\text { (micro e } \\
\text { pequena } \\
\text { empresa). }\end{array}$ & 59 & 17 & $\begin{array}{l}\mathrm{R} \$ 6,5 \\
\text { milhões }\end{array}$ & $\begin{array}{l}\mathrm{R} \$ 17,5 \\
\text { milhões }\end{array}$ \\
\hline
\end{tabular}

Fonte: Dados da pesquisa (2014)

Não distante dessa realidade, estão as empresas contempladas. A grande maioria delas está localizada na capital ou na região metropolitana. O percentual dessa distribuição chegava a $74 \%$ de empresas de Salvador, 8\% de Lauro de Freitas, 5\% de Camaçari e de 1 a 3\% das demais cidades.

O Gráfico 1 apresenta a distribuição das empresas por números de empresas contratadas e suas cidades de origem. 
Gráfico 1 - Distribuição das MPEs contempladas por cidades de origem (unid.)

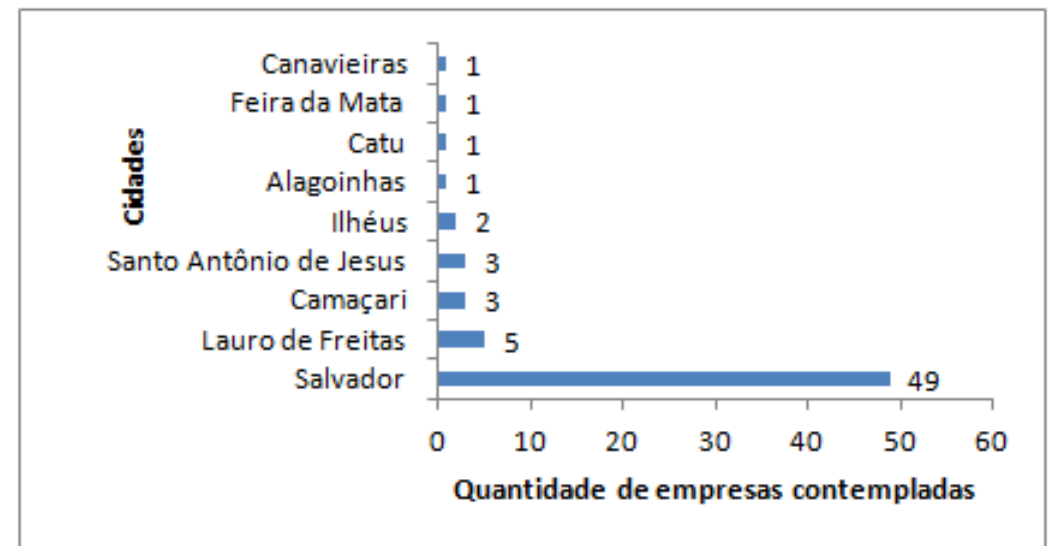

Fonte: Dados da pesquisa (2014)

Vale ressaltar que os editais da FAPESB foram destinados a temas inseridos na Política de Desenvolvimento Produtivo (PDP), em consonância com a Política Estadual de Ciência, Tecnologia e Inovação e, ainda, do interesse do Programa Bahia de Inovação (FAPESB, 2008c). temas:

De acordo com os editais, as propostas submetidas deveriam estar inseridas nos seguintes

TEMA 1: Biotecnologia, biodiversidade, agronegócio, fármacos, cosméticos e saúde. TEMA 2: Nanotecnologia, semicondutores e tecnologia da informação e comunicação. TEMA 3: Biocombustíveis, energias e meio ambiente.

TEMA 4: Engenharias e novos materiais (FAPESB, 2009).

Das empresas contempladas, $68 \%$ eram micro empresas e $32 \%$ eram de pequeno porte. Essas empresas eram, em maioria, da área de Tecnologia da Informação (TI), que corresponderam a 50\% das empresas contempladas; seguidas das de Engenharia, com 24\%; do Agronegócio, com 13\%; e de Biotecnologia, com 7\% (FAPESB, 2008a; 2008b; 2008c; 2009; 2010a; 2010b; 2011).

\section{METODOLOGIA}

Para o desenvolvimento da pesquisa e elaboração do presente artigo, foram utilizadas tanto fontes de dados primárias de caráter quantitativo, quanto secundárias.

No que se refere à fonte primária, foram elaborados questionários on-line estruturados ou fechados, aplicados às empresas contempladas nos editais de subvenção econômica 001/2008, 017/2008, 008/2010 e 023/2010 da FAPESB.

Os dados a respeito das empresas contempladas foram disponibilizados pela FAPESB, que forneceu como dados nome do coordenador do projeto, nome da empresa proponente, telefone, e-mail, cidade, porte, data inicial e data final de execução do projeto.

Os questionários foram lotados em um site para onde o entrevistado, ao receber o link do questionário por e-mail, era direcionado.

Das 59 empresas contempladas, que receberam a solicitação para participar da pesquisa, 28 responderam ao questionário, representando $47,45 \%$ da população total.

O período em que os questionários ficaram disponíveis foi de 28 de agosto de 2013 a 30 de setembro de 2013.

Em relação à fonte secundária de dados, foram utilizadas pesquisas científicas tanto em formato de artigo científico quanto dissertações de mestrado, teses de doutorado e livros da área, além da análise detalhada dos editais de subvenção econômica da FAPESB estudados neste trabalho.

\section{RESULTADO DOS QUESTIONÁRIOS E DISCUSSÕES}

O questionário enviado às empresas teve como objetivo avaliar quais foram as principais dificuldades e facilidades encontradas pelas empresas durante o processo de participação nos editais 
da FAPESB, bem como no desenvolvimento do projeto após o repasse do recurso. Ainda objetivou conhecer as motivações de mercado e o impacto das inovações geradas dentro da empresa.

Quando perguntadas sobre como obtiveram informações a respeito do edital de subvenção econômica, das 28 empresas que responderam, dez tiveram como fonte de informação a internet, sete conheceram o edital por intermédio de terceiros e seis pela universidade. Vale ressaltar que nem o SEBRAE nem as Incubadoras foram citadas como fontes de informação, o que pode corroborar para a ideia de que houve uma fraca parceria estratégica entre a FAPESB e outras instituições para a divulgação dos editais PAPPE estudados no presente trabalho. A Tabela 1 apresenta as respostas das empresas acerca das fontes de informação dos editais.

Tabela 1 - Fontes de informação das empresas por quantidade de resposta e porcentagem

\begin{tabular}{lcc}
\hline \multicolumn{1}{c}{ Fonte de informação } & $\begin{array}{c}\text { Qtde. de } \\
\text { respostas }\end{array}$ & $\%$ \\
\hline Internet (e-mail, Facebook, página da FA- & 10 & 35,71 \\
PESB, outros sites) & 7 & 25,00 \\
Terceiros (clientes, fornecedores, amigos) & 6 & 21,43 \\
Universidade e/ou Institutos de pesquisa & 3 & 10,71 \\
Funcionário da empresa & 1 & 3,57 \\
Palestra, Congresso ou reuniões & 1 & 3,57 \\
Incubadora & 0 & - \\
Televisão e/ou Rádio & 0 & - \\
SEBRAE & 28 & 100 \\
Total & & \\
\hline
\end{tabular}

Fonte: Dados da pesquisa (2014)

No que concerne à elaboração da proposta submetida, quando questionadas se houve alguma assessoria para a redação do projeto, grande parte das empresas respondeu que apenas funcionários envolveram-se nessa tarefa (64\%); $25 \%$ responderam que foram contratadas empresas de consultoria para auxiliá-las; e $11 \%$ tiveram assessoria da universidade ou do Instituto de pesquisa. Nenhuma empresa citou a participação do SEBRAE ou da Incubadora na tarefa em questão.

As empresas contempladas que responderam ao questionário revelaram que, no momento da participação do edital, uma boa parcela delas - $44 \%$ - era formada por empresas jovens, de até dois anos. Das demais, 30\% eram empresas de três a cinco anos e 19\% de cinco a dez. Apenas $7 \%$ tinham mais de dez anos.

Em uma pergunta de múltipla escolha, quando questionadas se houve atraso nos prazos da FAPESB, duas alternativas foram as mais selecionadas. A primeira refere-se ao repasse dos recursos e a segunda à liberação dos resultados dos editais. O Gráfico 2 mostra a quantidade de respostas para cada alternativa.

Gráfico 2 - Respostas sobre atrasos ocorridos pela FAPESB

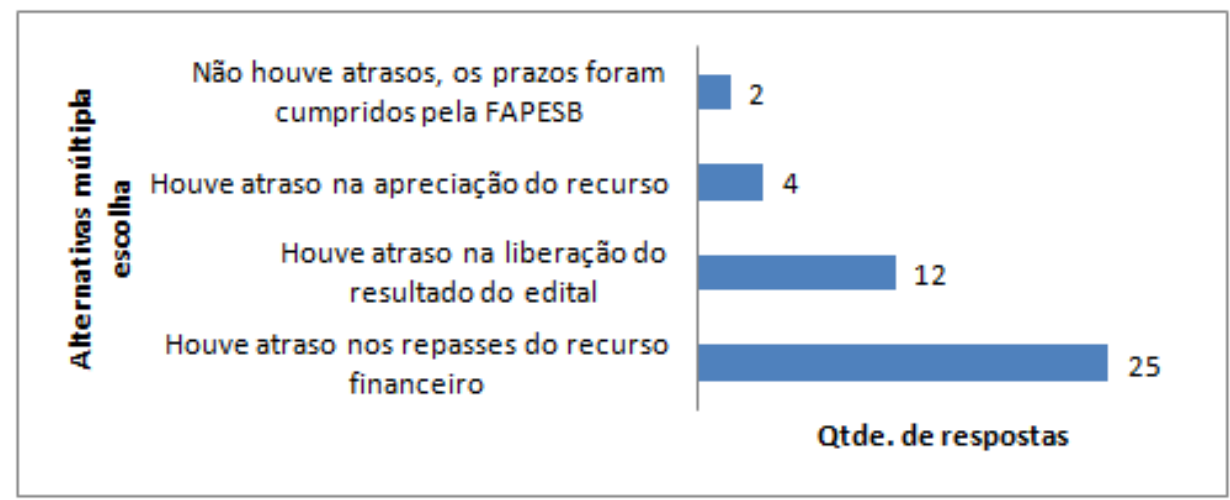

Fonte: Dados da pesquisa (2014) 
Em relação aos prazos dados pela FAPESB, praticamente todos os editais estudados sofreram alterações em seus prazos originais. O edital 017/2008 foi lançado em 12/12/2008, e os prazos para preenchimento on-line do formulário, divulgação dos resultados e contratação das propostas aprovadas eram, respectivamente, 27/03/2009, 01/06/2009 e 17/07/2009 (FAPESB, 2008b). Contudo, os prazos foram alterados para as seguintes datas: preenchimento do formulário on-line -24/04/2009; divulgação dos resultados - 05/06/2009; e contratação das propostas aprovadas - 01/09/2009 (FAPESB, 2013).

O mesmo aconteceu no edital 008/2010, em que o prazo para preenchimento do formulário online, divulgação do resultado e contratação das propostas aprovadas foi alterado. Segundo os dados fornecidos pela FAPESB (2013), a contratação das propostas não seguiu o previsto nas erratas dos editais. Todas as contratações definidas ocorreram fora do prazo estipulado. O Quadro 2 detalha as informações referentes aos prazos e suas alterações.

Quadro 2 - Prazos dos editais

\begin{tabular}{|c|c|c|c|c|c|c|c|c|}
\hline Edital & Abertura & \multicolumn{2}{|c|}{$\begin{array}{c}\text { Preenchimento } \\
\text { on-line }\end{array}$} & \multicolumn{2}{|c|}{$\begin{array}{c}\text { Divulgação do } \\
\text { resultado }\end{array}$} & \multicolumn{2}{c|}{$\begin{array}{c}\text { Contratação da } \\
\text { proposta (edital e } \\
\text { errata) }\end{array}$} & $\begin{array}{c}\text { Contratação } \\
\text { definitiva }\end{array}$ \\
\hline & & Original & Alterado & Original & Alterado & Original & Alterado $^{4}$ & \\
\hline $001 / 2008$ & $19 / 02 / 08$ & $21 / 05 / 08$ & -1 & $30 / 06 / 08$ & - & $31 / 07 / 08$ & - & $12 / 2008^{2}$ \\
\hline $017 / 2008$ & $12 / 12 / 08$ & $27 / 03 / 09$ & $24 / 04 / 09$ & $01 / 06 / 09$ & $05 / 06 / 09$ & $17 / 07 / 09$ & $01 / 09 / 09$ & $12 / 2009^{2}$ \\
\hline $008 / 2010$ & $14 / 04 / 10$ & $11 / 06 / 10$ & $30 / 06 / 10$ & $30 / 07 / 10$ & $13 / 08 / 10$ & $30 / 09 / 10$ & $29 / 10 / 10$ & $12 / 2010^{2}$ \\
\hline $023 / 2010$ & $27 / 08 / 10$ & $29 / 10 / 10$ & $12 / 11 / 10$ & $20 / 12 / 10$ & $21 / 01 / 11$ & $25 / 03 / 12$ & $31 / 03 / 11$ & $\begin{array}{c}\text { De } 09 / 2011 \text { a } \\
11 / 2011^{2}\end{array}$ \\
\hline
\end{tabular}

Fonte: Elaborado pelos autores com dados da pesquisa (2014)

${ }^{1}$ Não foram encontradas informações sobre alterações nas datas e prazos do edital 001/2008.

${ }^{2}$ Foram considerados apenas o mês e ano da contratação definitiva das propostas.

${ }^{3}$ Data prevista no edital.

${ }^{4}$ Data prevista na errata.

Como visto pelo levantamento de dados apresentados, todas as atividades referentes aos editais PAPPE foram executadas fora do prazo. Desde a publicação dos resultados dos editais, contratação das propostas, repasse de recurso, até o próprio prazo para desenvolvimento do projeto.

O item a respeito dos prazos dos editais e de suas alterações possui uma grande relevância, uma vez que os projetos de inovação desenvolvidos pelas empresas, em sua maioria, objetivam criar novas oportunidades de negócio/mercado e ganho de competitividade.

Uma vez que ocorrem atrasos, seja no repasse de recurso, seja na própria execução do projeto, a empresa perde potencial de competitividade, correndo o risco inclusive de outras empresas lançarem produtos similares à inovação pretendida.

As dificuldades apontadas pelas empresas como as principais encontradas durante o processo de interação com a FAPESB foram o excesso de burocracia, seguida do atraso no repasse dos recursos e a exigência da contrapartida. A Tabela 2 apresenta as dificuldades relacionadas pelas MPEs.

Tabela 2 - Relação das principais dificuldades encontradas pelas empresas

\begin{tabular}{lcc}
\hline \multicolumn{1}{c}{ Dificuldades } & Respostas & $\%$ \\
\hline Atraso no repasse do recurso financeiro & 18 & 69,23 \\
Burocracia excessiva & 17 & 65,38 \\
Exigência da contrapartida & 9 & 34,62 \\
Atraso no cumprimento dos prazos & 6 & 23,08 \\
Falta de informação clara e precisa & 5 & 19,23 \\
$\begin{array}{l}\text { A empresa não estava preparada para desenvolver um } \\
\text { projeto de inovação tecnológica }\end{array}$ & 3 & 11,54 \\
$\begin{array}{l}\text { O pouco tempo entre a abertura do edital e a submissão da } \\
\text { proposta }\end{array}$ & 1 & 3,85 \\
Total & 26 & 100,00 \\
\hline
\end{tabular}

Fonte: Dados da pesquisa (2014) 
Os editais da FAPESB passaram por modificações significativas ao longo dos anos, sobretudo no que tange às demandas de documentos, exigência de contrapartida e do conteúdo das propostas.

De acordo com Ferreira (2012), os editais de subvenção econômica são os mais complexos da FAPESB, exigindo do proponente não apenas conhecimentos científicos e tecnológicos, mas também de mercado. Complementarmente, a quantidade de documentos exigidos supera a de qualquer outro edital da instituição.

Ferreira (2012) alerta para o fato de que o grau de complexidade dos editais é tão alto que, em alguns casos, pode ser mais alto que as competências comumente encontradas nas MPEs.

Ainda, deve-se levar em conta que o grau de escolaridade nas MPEs baianas, em que a grande maioria do pessoal possui apenas curso médio completo ou superior incompleto $(45,2 \%)$ e apenas $8,4 \%$ possuem curso superior completo (SEBRAE, 2012), o grau de complexidade dos editais de subvenção pode ser apresentado como uma barreira ao acesso a financiamentos a essas empresas, uma vez que a própria competência para elaboração da proposta pode ser apresentada como uma carência.

Se, por um lado, há uma deficiência no grau de formação das pessoas ocupadas nas MPEs, por outro, igualmente existe outra questão que se apresenta como barreira: a disponibilidade de recursos humanos.

Na Bahia, 75,61\% das MPEs possuem de 0 a 4 funcionários (IBGE, 2013). Isso indica que a estrutura de trabalhadores já é bastante enxuta, o que não possibilita a tais empresas a dedicação exclusiva dos seus funcionários ou do proprietário para elaboração da proposta ou levantamento de todos os documentos exigidos. Esses dados devem ser observados no momento da elaboração dos editais destinados às MPEs.

A dificuldade apontada como a terceira mais forte é a exigência da contrapartida. Vale ressaltar que, nos primeiros editais da FAPESB, a contrapartida exigida era de, no mínimo, $30 \%$ do valor solicitado.

Comparando os resultados das pesquisas realizadas por Maçaneiro (2008) e CGEE (2007), em que o objetivo era analisar, sob a perspectiva das empresas contempladas, os editais de subvenção econômica, a contrapartida é um ponto de conflito.

A pesquisa de Maçaneiro (2008) buscou avaliar os editais de subvenção econômica por meio de pesquisa de campo com empresas paranaenses que participaram desse programa em 2007.

De acordo com a autora, as empresas apontaram a contrapartida como um incentivo às MPEs aos recursos públicos para inovação. Isso porque, segundo as empresas, os percentuais operados nos editais eram cerca de $5 \%$, bem menores que os destinados às empresas de médio e grande porte. Além disso, a contrapartida também era possível na modalidade não financeira, o que facilitava a participação das MPEs.

Já o estudo desenvolvido pelo CGEE consultou 451 empresas que participaram do primeiro edital de subvenção econômica lançado pela FINEP. O intuito era conhecer os mais distintos aspectos relacionados ao edital, especialmente em relação ao processo, com o intento de nortear as futuras edições.

Os dez critérios de exigência do edital foram, no geral, julgados adequados por mais de $60 \%$ das empresas respondentes. Alguns critérios foram diversamente apreciados por empresas de determinados portes. As MPEs demonstraram maior resistência ao quesito: aporte de contrapartida (CGEE, 2007).

Em uma análise específica aos editais da FAPESB, estes apresentaram valores de contrapartida bem maiores que os exigidos nos editais da FINEP, por exemplo. Enquanto o edital de subvenção econômica da FINEP prevê $5 \%$ de contrapartida para as MPEs, os da FAPESB iniciaram com $30 \%$ de contrapartida. Apenas o último, 023/2010, exigiu aporte de $10 \%$.

De uma forma geral, os itens excesso de burocracia e exigência de contrapartida são vistos como maiores obstáculos para que as MPEs tenham acesso ao financiamento. Ferreira (2012) argumenta que obviamente o recurso público para inovação não pode ser repassado às empresas que não apresentem competências suficientes para executar tais projetos. Entretanto, segundo o autor, as políticas públicas de fomento à inovação às MPEs não podem ser distantes da realidade das referidas empresas, perdendo, assim, sua efetividade.

De acordo com alguns autores como Camargos et al. (2010), a inclusão de uma nova gama de fatores para análise de crédito às MPEs poderá facilitar o acesso ao financiamento sem comprometer a análise da competência da empresa, nem aumentar o risco de inadimplência. Os fatores para análise defendidos pelos autores são (i) nível de escolaridade do proprietário, (ii) tempo de funcionamento da empresa, (iii) experiência anterior do proprietário no setor, (iv) localização da empresa, (v) nível 
de tecnologia nos seus processos e (vi) finalidade do crédito. Conforme os autores, a inclusão desses critérios traria um enorme benefício ao processo de apoio às MPEs.

Outro aspecto questionado à empresa foi o teor de inovação dos projetos. Para avaliar até que ponto o recurso do edital PAPPE incentivaria a empresa a desenvolver novos projetos de inovação, foi questionado ao entrevistado se o projeto submetido à FAPESB fazia parte de uma linha de pesquisa já existente na empresa ou se era o desenvolvimento de algo novo. Sessenta e cinco por cento dos respondentes disseram que se tratava de algo novo para a empresa, e 35\% disseram que era uma linha já existente.

Do mesmo modo, foi questionado se a empresa já concorreu a outros editais de subvenção econômica. A pergunta era de múltipla escolha, podendo, por conseguinte, uma empresa ter participado de mais de um edital. Vale ressaltar que nenhuma empresa concorreu ao edital de subvenção econômica destinado à exportação. Esse edital é uma parceria entre o MDIC e o MCTI para incentivar as MPEs a promoverem inovações em seus produtos, adequando-os às normas ou níveis de seus concorrentes internacionais. O edital é de fluxo contínuo, com valor máximo de R\$ 30 mil e contrapartida de $10 \%$. A ausência de respostas nesse item pode indicar a pouca vocação exportadora ou para a falta de conhecimento de mais uma possibilidade de edital de subvenção econômica. A Tabela 3 mostra a quantidade de respostas para cada alternativa fornecida.

Tabela 3 - Empresas contempladas que já participaram de outros editais de subvenção

\begin{tabular}{lc}
\hline \multicolumn{1}{c}{ Editais } & Respostas \\
\hline Não, o único edital foi o PAPPE & 7 \\
Sim, outra edição do PAPPE & 9 \\
Sim, Pesquisador na empresa - FAPESB & 4 \\
Sim, Cooperação ICT e Empresa - FAPESB & 6 \\
Sim, Inovação Aberta - FAPESB & 2 \\
Sim, outros editais da FINEP & 9 \\
Sim, programa de exportação do MDIC & 0 \\
Outros & 4 \\
\hline
\end{tabular}

Fonte: Dados da pesquisa (2014)

A presente pesquisa também teve como objetivo conhecer a motivação da empresa em desenvolver um projeto de inovação para atingir um mercado em potencial. Esse mercado poderia ser local, nacional e/ou internacional. E, ainda, saber qual o impacto gerado na receita das empresas dos resultados gerados pelos projetos.

Quando questionadas sobre em qual mercado foi lançado o produto resultado do projeto, as respostas foram as seguintes: $16 \%$ lançaram no mercado local; $8 \%$ no nacional; $8 \%$ no internacional; e $12 \%$ nos mercados local, nacional e internacional. A maioria dos respondentes, $32 \%$, alegou que nenhum produto havia sido lançado no mercado em virtude de necessidades de ajustes, e $20 \%$ argumentaram que o projeto ainda está em fase de finalização.

Já no quesito impacto gerado na receita, a maioria respondeu que não houve lançamento de produto (60\%), outros $24 \%$ revelaram que o produto lançado gerou uma receita de 0,1 a $10 \%$ para a empresa e $16 \%$ disseram que obtiveram de $10,1 \%$ a $20 \%$ de aumento na receita da empresa.

O grande índice de empresas que ainda não lançaram produtos no mercado provavelmente se deve a dois fatores. Primeiramente, a data de finalização dos projetos. Cinquenta e um por cento dos projetos foram finalizados entre 2011 e 2012, e 41\% foram ou serão finalizados entre 2013 e 2014. Essas datas ainda são muito recentes para que as empresas consigam transformar os resultados da pesquisa em produtos lançados no mercado.

O segundo fator é a própria dificuldade que as MPEs possuem em investir na elaboração de estratégias para o lançamento do produto no mercado. Muitas vezes, o esforço é duplo. Primeiramente no desenvolvimento da pesquisa e depois no lançamento, necessitando, muitas vezes, de novos financiamentos para a segunda etapa.

A última pergunta do questionário referiu-se a quais aspectos foram gerados à empresa a partir da sua participação no edital PAPPE.

O desenvolvimento de novos projetos de pesquisa liderou as respostas dos entrevistados, seguido de aumento da competitividade, atuação em novos mercados e fortalecimento da marca. A 
Tabela 4 apresenta as alternativas e quantidade de resposta das empresas.

Observa-se que, dentre as respostas, seis empresas revelaram ter havido geração de pedido de patente a partir dos projetos desenvolvidos. Esse é um item importante para medir o grau de inovação fomentada pela FAPESB, além de contribuir para o indicador de inovação do estado da Bahia.

Tabela 4 - Benefícios para a empresa pela participação no edital de subvenção

\begin{tabular}{lc}
\hline \multicolumn{1}{c}{ Alternativas } & Respostas \\
\hline $\begin{array}{l}\text { Desenvolvimento de novos projetos de } \\
\text { pesquisa }\end{array}$ & 18 \\
Aumento de competitividade & 14 \\
Atuação em novos mercados & 13 \\
Fortalecimento da marca & 11 \\
Geração de patente para a empresa & 6 \\
Não houve nenhum impacto significativo & 3 \\
Internacionalização da empresa & 1 \\
\hline
\end{tabular}

Fonte: Dados da pesquisa (2014)

Além disso, as patentes geradas por empresas representam um grande peso nos ativos intangíveis da organização, trazendo consequências não apenas na competitividade perante o mercado, mas também agregando valor à sua marca.

A participação em editais de inovação é um estímulo para que a empresa desenvolva novos projetos de $P \& D$, mas também é uma oportunidade para ela aumentar sua competitividade e atuação no mercado (seja mercado já estabelecido, seja um novo).

\section{CONCLUSÃO}

Os editais de subvenção econômica destinados às MPEs são um reflexo da importância dada pelo poder público a essa modalidade de empresa. No cenário das empresas baianas que participaram do processo seletivo para obtenção do recurso da FAPESB, elas enfrentaram algumas dificuldades e elencaram como principais o excesso de burocracia, a exigência de contrapartida e os atrasos no cumprimento dos prazos da FAPESB, sobretudo do repasse dos recursos. Como oportunidades, as empresas apontaram o desenvolvimento de novos projetos de pesquisa, aumento do potencial competitivo, abrangência de novos mercados e fortalecimento das suas marcas. Entretanto, vale ressaltar que os editais por si só não são capazes de elevar as MPEs a diferentes patamares competitivos, visto que, no panorama geral, as MPEs possuem uma frágil estrutura, seja de capital financeiro, seja de recursos humanos, ou ainda de acesso a novas tecnologias.

Em virtude desse quadro, seria interessante que fossem elaborados, por diferentes agentes públicos ou privados, planos estratégicos que envolvessem ações de empreendedorismo, capacitação empresarial em gestão da inovação, capacitação em elaboração de projetos a esse grupo de empresas. O objetivo seria proporcionar um suporte às MPEs na sua participação nos editais de subvenção econômica, bem como no desenvolvimento dos projetos aprovados. Isso auxiliaria a criação de uma expertise para as MPEs no quesito gestão da inovação, além do próprio fortalecimento dessas empresas relativamente à sua estrutura no que se refere, principalmente, aos recursos humanos com maior nível de escolaridade.

Com respeito especificamente aos editais de subvenção estudados neste trabalho, conclui-se que a pouca quantidade de empresas participantes dos editais, o declínio do número de propostas submetidas e o baixo número de projetos contemplados podem estar ligados a fatores como a frágil estratégia de divulgação dos editais, o aumento da complexidade dos editais (seja quanto à exigência de documentação, seja quanto ao teor do conteúdo das propostas) e a dificuldade das MPEs de elaborarem boas propostas em razão de sua fragilidade estrutural.

No cenário nacional, as MPEs destacam-se pela participação na economia brasileira, principalmente pela possibilidade de geração de emprego e renda no país. As MPEs baianas também possuem destacada importância no desenvolvimento socioeconômico do estado, e a inclusão delas em programas de fortalecimento produtivo por meio do fomento à inovação, como é o caso dos 
editais de subvenção econômica, pode representar um grande ganho para a sociedade do estado da Bahia.

No entanto, é importante que as instituições públicas, além do próprio Governo do estado, percebam as limitações, carências e fragilidades das MPEs e formulem políticas e programas que, adaptados a essa realidade específica, possam ao mesmo tempo potencializar os investimentos de recursos públicos e diminuir as barreiras e obstáculos vivenciados pelas MPEs.

\title{
FOSTERING INNOVATION IN MICRO AND SMALL ENTERPRISES: ASSESSMENT OF COMPANIES FROM BAHIA STATE ON FAPESB'S ECONOMIC SUBVENTION CALLS FOR PROPOSALS
}

\begin{abstract}
The objective of this study was to identify the main difficulties and opportunities experienced by enterprises that have applied to the Fundação de Amparo à Pesquisa do Estado da Bahia's (FAPESB) Economic Subvention calls for proposals. In order to achieve the objectives, we interviewed companies that have received grants through the FAPESB's calls for proposals 001/2008, 017/2008, 008/2010 and $023 / 2010$, and we have also made an analysis of these calls. The main difficulties reported by the enterprises interviewed were excessive bureaucracy, the requirement of counterpart and delays in the deadlines of FAPESB, especially regarding the transfer of funds. The enterprises pointed out as opportunities the development of new research projects, the increase of the competitive potential, the reaching of new markets and the strengthening of their brands. The main identified threat was the possibility of inadequacy of the calls for proposals to the particular reality presented by micro and small enterprises (SME) in Bahia. It is expected that this research can provide subsidies and contributions to the development and strengthening of public policies aimed at the development of SME, especially in achieving public support for innovation.
\end{abstract}

Keywords: Innovation management. Economic subvention. Small and medium enterprise.

\section{REFERÊNCIAS}

ANDRADE, A. Z. B. Estudo Comparativo entre a Subvenção Econômica à Inovação operada pela FINEP e programas correlatos de subsídios em países desenvolvidos. Dissertação (Mestrado) Escola Brasileira de Administração Pública e de Empresas, Fundação Getúlio Vargas, Rio de Janeiro, 2009.

ASSOCIAÇÃO NACIONAL DE PESQUISA E DESENVOLVIMENTO DAS EMPRESAS INOVADORAS (ANPEI). Guia Prático de Apoio à Inovação. [2009]. Disponível em: <http://proinova.isat.com.br/ Downloads.asp >. Acesso em: 10 out. 2013.

BRASIL. Lei no 11.077, de 30 de dezembro de 2004. Altera a Lei no 8.248, de 23 de outubro de 1991, a Lei no 8.387, de 30 de dezembro de 1991, e a Lei no 10.176, de 11 de janeiro de 2001, dispondo sobre a capacitação e competitividade do setor de informática e automação e dá outras providências [2004a]. Disponível em: <http://www.planalto.gov.br/ccivil_03/_Ato2004-2006/2004/ Lei/L11077.htm>. Acesso em: 10 out. 2013.

BRASIL. Lei n. 10.973, de 2 de dezembro de 2004. Dispõe sobre incentivos à inovação e à pesquisa científica e tecnológica no ambiente produtivo e dá outras providências. [2004b]. Disponível em: <http://www.planalto.gov.br/ccivil_03/_ato2004-2006/2004/lei//10.973.htm>. Acesso em: 10 out. 2013.

BRASIL. Lei no 11.196, de 21 de novembro de 2005. Institui o Regime Especial de Tributação para a Plataforma de Exportação de Serviços de Tecnologia da Informação - REPES, o Regime Especial de Aquisição de Bens de Capital para Empresas Exportadoras - RECAP e o Programa de Inclusão Digital [2005]. Disponível em: <http://www.planalto.gov.br/ccivil_03/_ato2004-2006/2005/lei/ 111196.htm>. Acesso em: 10 out. 2013. 
de 2005, para incluir novo incentivo à inovação tecnológica e modificar as regras relativas à amortização acelerada para investimentos vinculados à pesquisa e ao desenvolvimento [2007]. Disponível em: <http://www.planalto.gov.br/ccivil_03/_ato2007-2010/2007/lei/l11487.htm>. Acesso em: 10 out. 2013.

BRASIL. Lei no 11.174 de 09 de dezembro de 2008. Dispõe sobre incentivos à inovação e à pesquisa científica e tecnológica em ambiente produtivo no Estado da Bahia e dá outras providências [2008]. Disponível em: < http://www.cra-ba.org.br/Adm/FCKimagens/ F\%C3\%B3rum\%20ME\%20e\%20EPP/Lei\%20de\%20Inova\%C3\%A7\%C3\%A30\%20n\%C2\%BA_\%20 11_174\%202008.pdf>. Acesso em: 10 out. 2013.

CAMARGOS, M. A. et al. Fatores condicionantes de inadimplência em processos de concessão de crédito a Micro e Pequenas Empresas do Estado de Minas Gerais. Revista de Administração Contemporânea, Curitiba, v. 14, n. 2, p. 333-352, mar./abr. 2010.

CENTRO DE GESTÃO E ESTUDOS ESTRATÉGICOS (CGEE). Apreciação da Chamada 2006 do Programa de Subvenção Econômica à Inovação. Brasília: CGEE, 2007.

CORAL, E. et al. Visão geral da metodologia NUGIN. In: CORAL, E.; OGLIARI, A.; ABREU, A. F. (Org.). Gestão Integrada da Inovação: Estratégia, Organização e Desenvolvimento de Produtos. São Paulo: Atlas, 2011. p. 28-44.

CORAL, E.; GEISLER, L. Motivação para a Inovação. In: CORAL, E.; OGLIARI, A.; ABREU, A. F. (Org.). Gestão Integrada da Inovação: Estratégia, Organização e Desenvolvimento de Produtos. São Paulo: Atlas, 2011. p. 14-27.

CORDER, S. Políticas de Inovação Tecnológica no Brasil: Experiência recente e perspectivas. Instituto de Pesquisa Economica Aplicada. Texto para Discussão, n. 1.244, p. 7-34. Brasília, 2006.Disponível em: <http://www.ipea.gov.br/portal/index.php?option=com_content\&view=article\&id=4489> Acesso em: 10 out. 2013.

FAPESB. EDITAL BAHIA INOVAÇÃO/FAPESB/SECTI/FINEP/MCTI - 001/2008. [2008a]. Disponível em: <http://www.fapesb.ba.gov.br/wp-content/uploads/2011/02/ EDITAL-001_08-PAPPE.pdf>. Acesso em: 10 out. 2013.

EDITAL BAHIA INOVAÇÃO/FAPESB/SECTI/FINEP/MCTI - 017/2008. [2008b].

Disponível em: <http://www.fapesb.ba.gov.br/wp-content/uploads/2010/08/ Edital-Pappe.pdf>. Acesso em: 10 out. 2013.

EDITAL BAHIA INOVAÇÃO - 017/2008-MODALIDADE PAPPE SUBVENÇÃO -

ERRATA03. [2008c]. Disponível em: <http://www.fapesb.ba.gov.br/ wp-content/uploads/2010/08/ Errata-03-Edital-Pappe.pdf>. Acesso em: 10 out. 2013.

Relatório de Gestão 2009. [2009]. Disponível em: <http://www.fapesb.ba.gov.br/wpcontent/uploads/2010/10/Relat\%C3\%B3rio-de-Gest\%C3\% A3o-Fapesb-2009.pdf $>$. Acesso em: 31 out. 2013.

EDITAL/FAPESB/SECTI/FINEP/MCTI - 008/2010. [2010a]. Disponível em: <http:// www.aioninnovations.com/works/pdfs/EDITAL0082010_PAPPE.pdf>. Acesso em: 10 out. 2013.

EDITAL BAHIA INOVAÇÃO - FAPESB/SECTI/FINEP/MCTI - 023/2010. [2010b]. Disponível em: <http://www.fapesb.ba.gov.br/wp-content/uploads/2010/12/ Edital-023-2010PAPPE-Integra\%C3\%A7\%C3\%A3o.pdf>. Acesso em: 10 out. 2013.

Relatório de Gestão de 2011. [2011]. Disponível em: <http://www.fapesb.ba.gov.br/ wp-content/uploads/2012/05/Relat\%C3\%B3rio-de-Gest\%C3\% A3o-Fapesb-2011.pdf>. Acesso em: 31 out. 2013.

Data de contratação e finalização dos projetos aprovados nos editais PAPPE 001/2008, 017/2008, 008/2010 e 023/2010. Dados não publicados. [2013]. E-mail pessoal recebido em 23 ago. 2013.

FERREIRA, D. L. O Sistema de Inovação do Estado da Bahia: uma análise baseada em indicadores 
de tecnologia e inovação. Dissertação (Mestrado) - Faculdade de Tecnologia SENAI/CIMATEC, Salvador, 2012.

FINANCIADORA DE ESTUDOS E PROJETOS (FINEP). Manual do Programa Subvenção Econômica à Inovação Nacional. Brasília: FINEP, 2013. Disponível em: <http://download.finep.gov.br//manuais/ manualSubvencao2010.pdf>. Acesso em: 4 out. 2013.

FONSECA, S. A.; KRUGLIANSKAS, I. Inovação em microempresas de setores tradicionais: estudo de casos em incubadoras brasileiras. In: SBRAGIA, R.; STAL, E. (Ed.). Tecnologia e inovação: experiência de gestão na micro e pequena empresa. São Paulo: PGT/USP, 2002. p. 89-109.

HOLANDA, F. C. S. et al. Gestão de Inovação: Comparação de duas realidades distintas Universidade Estadual de Santa Cruz (Ilhéus, Bahia) e Universidade de La Rochelle (França). Anais SIMTEC, Aracaju, v. 1, n. 1, p. 276-289, 2013.

INSTITUTO BRASILEIRO DE GEOGRAFIA E ESTATÍSTICA (IBGE). Sistema IBGE de recuperação Automática (SIDRA). Tabela 987 - Empresas e outras organizações, pessoal ocupado total e assalariado em 31.12, salários e outras remunerações e salário médio mensal, por seção, divisão e grupo da classificação de atividades (CNAE 2.0) e faixas de pessoal ocupado total. [2013]. Disponível em: <http://www.sidra.ibge.gov.br>. Acesso em: 10 out. 2013.

LIMA, M. C.; TEIXEIRA, F. L. C. Inserção de um agente indutor da relação universidade-empresa em sistema de inovação fragmentado. Revista de Administração Contemporânea, Curitiba, v. 5, n. 2, p.135-155, 2001.

MAÇANEIRO, M. B. Fontes de financiamento à inovação: incentivos e óbices às micro e pequenas empresas - estudo de casos múltiplos no estado do Paraná. Dissertação (Mestrado) - Universidade Federal do Paraná, Curitiba, 2008.

MORAIS, J. M. Programas especiais de crédito para micro, pequenas e médias empresas: BNDES, Proger e Fundos Constitucionais de Financiamento. In: DE NEGRI, J. A.; KUBOTA, L. C. (Org.). Políticas de Apoio à Inovação Tecnológica no Brasil. Brasília: Instituto de Pesquisa Econômica Aplicada, v. 1, 2008a. p. 389-433.

MORAIS, J. M. Uma Avaliação de programas de apoio financeiro à inovação tecnológica com base nos fundos setoriais e na Lei de Inovação. In: DE NEGRI, J. A.; KUBOTA, L. C. (Org.). Políticas de

Apoio à Inovação Tecnológica no Brasil. Brasília: Instituto de Pesquisa Econômica Aplicada, v. 1, 2008b. p. 67-105.

PEREIRA, N. M.; FIGUEIREDO, S. P. Experiência de apoio à Inovação Tecnológica Setorial. Journal of Technology Management \& Innovation, Universidad de Talca, v. 1, n. 3, p. 74-80, 2006.

SECRETARIA DE CIÊNCIA E TECNOLOGIA DO ESTADO DA BAHIA (SECTI). Lei de Inovação da Bahia, Lei $\mathbf{n}^{\circ} 11.174$ de 09 de Dezembro de 2008. Dispõe sobre incentivos à inovação e à pesquisa científica e tecnológica em ambiente produtivo no Estado da Bahia e dá outras providências. [2008]. Disponível em: <http://www.secti.ba.gov.br/leis-incentivo/lei-de-inovacao-da-bahia>. Acesso em: 10 out. 2013.

SERVIÇO BRASILEIRO DE APOIO ÀS MICRO E PEQUENAS EMPRESAS (SEBRAE). Anuário do trabalho na micro e pequena empresa. 5. ed. Brasília: Departamento Intersindical de Estatística e Estudos Socioeconômicos, 2012. Disponível em: <http://bis.sebrae.com.br/GestorRepositorio/ARQUIVOS CHRONUS/bds/bds.nsf/8cb2d324ffde890ece700a5fb073c4da/\$File/4246.pdf>. Acesso em: 13 out. 2013. 